\title{
Identification and functional characterisation of Complement Regulator Acquiring Surface Protein-1 of serum resistant Borrelia garinii OspA serotype 4
}

\author{
Nathalie D van Burgel ${ }^{1 *}$, Peter Kraiczy ${ }^{2}$, Tim J Schuijt ${ }^{1}$, Peter F Zipfel ${ }^{3}$, Alje P van Dam ${ }^{1}$
}

\begin{abstract}
Background: B. burgdorferi sensu lato $(\mathrm{sl})$ is the etiological agent of Lyme borreliosis in humans. Spirochetes have adapted themselves to the human immune system in many distinct ways. One important immune escape mechanism for evading complement activation is the binding of complement regulators Factor $\mathrm{H}$ (CFH) or Factor H-like protein1 (FHL-1) to Complement Regulator-Acquiring Surface Proteins (CRASPs).

Results: We demonstrate that B. garinii OspA serotype 4 (ST4) PBi resist complement-mediated killing by binding of FHL-1. To identify the primary ligands of FHL-1 four CspA orthologs from B. garinii ST4 PBi were cloned and tested for binding to human $\mathrm{CFH}$ and FHL-1. Orthologs BGA66 and BGA71 were found to be able to bind both complement regulators but with different intensities. In addition, all CspA orthologs were tested for binding to mammalian and avian CFH. Distinct orthologs were able to bind to CFH of different animal origins.
\end{abstract}

Conclusions: $B$. garinii ST4 PBi is able to evade complement killing and it can bind FHL-1 to membrane expressed proteins. Recombinant proteins BGA66 can bind FHL-1 and human CFH, while BGA71 can bind only FHL-1. All recombinant CspA orthologs from B. garinii ST4 PBi can bind CFH from different animal origins. This partly explains the wide variety of animals that can be infected by B. garinii.

\section{Background}

Borrelia burgdorferi sensu lato (sl), the etiologic agent of Lyme borreliosis, is a genetically diverse species. The different genospecies of $B$. burgdorferi sl appear to be associated with different manifestations of the disease $[1,2]$. B. burgdorferi sensu stricto (ss) is more common in North America but also found in Eurasia and is associated with arthritis, while B. garinii and B. afzelii are only present in Eurasia and are more commonly associated with Lyme neuroborreliosis and cutaneous manifestations, respectively. Specifically $B$. garinii OspA serotype 4 (ST4) strains, a genetically homogenous group, are frequently observed as a causative agent of neuroborreliosis in adults in Europe [3-6]. Recently it has also been proposed, though not yet generally accepted, to delineate the $B$. garinii ST4 strains as a separate species, $B$. bavariensis, due to large differences

\footnotetext{
* Correspondence: n.d.van_burgel@lumc.nl

'Department of Medical Microbiology, Centre of Infectious Diseases, Leiden
} University Medical Centre, PO Box 9600, 2300 RC, Leiden, the Netherlands compared to B. garinii non-ST4 in multilocus sequence analysis (MLSA) on several housekeeping genes [7].

The different human pathogenic genospecies are associated with certain human serum resistance profiles; the majority of $B$. burgdorferi ss and B. afzelii strains are relatively resistant to human serum, while most $B$. garinii strains are highly sensitive to complement-mediated killing in vitro. Among B. garinii, the ST4 strains showed a similar resistant profile as B. burgdorferi ss and B. afzelii [8-10].

B. burgdorferi sl has developed a variety of immune evasion strategies, among which the binding of two host-derived fluid-phase regulators of complement: Factor $\mathrm{H}(\mathrm{CFH})$ and Factor H-like protein 1 (FHL-1). $\mathrm{CFH}$ and FHL-1 the main immune regulators of the alternative pathway of complement activation, are structurally related proteins composed of several protein domains termed short consensus repeats (SCRs) [11]. $\mathrm{CFH}$ is a $150-\mathrm{kDa}$ glycoprotein composed of 20 SCR domains. In contrast, FHL- 1 is a $42-\mathrm{kDa}$ glycoprotein corresponding to a product of an alternatively
Ciomed Central

(c) 2010 van Burgel et al; licensee BioMed Central Ltd. This is an Open Access article distributed under the terms of the Creative Commons Attribution License (http://creativecommons.org/licenses/by/2.0), which permits unrestricted use, distribution, and reproduction in any medium, provided the original work is properly cited. 
spliced transcript of the $c f h$ gene and consists of seven SCRs. The seven N-terminally located SCRs of both complement regulators are identical with the exception of four additional amino acids at the $\mathrm{C}$-terminus of FHL-1 [12]. CFH and FHL-1 in the human host are responsible for preventing binding of factor $\mathrm{B}$ to $\mathrm{C} 3 \mathrm{~b}$, supporting the dissociation of the $\mathrm{C} 3 \mathrm{bBb}$ complex and acting as a cofactor for factor I-mediated cleavage of $\mathrm{C} 3 \mathrm{~b}$, the central component of the three complement activation pathways [12-15].

Serum resistant Borrelia acquire CFH and/or FHL-1 by direct interaction with outer surface proteins designated CRASPs (Complement Regulator-Acquiring Surface Proteins) [16]. Previously, five different CRASPs have been described for B. burgdorferi ss and B. afzelii. The CFH and FHL-1 binding CspA protein is (also designated CRASP-1) encoded by $\operatorname{csp} A$, a gene located on the lp54 plasmid. Although the lp54 plasmid of $B$. burgdorferi and $B$. afzelii carries multiple genes encoding a number of paralogous proteins, also called the gbb54 orthologous family, only the CspA is capable of binding human CFH and FHL-1 [17]. CspA is upregulated by spirochetes during the tick-mammalian transmission stage and down regulated during persistent infection $[18,19]$. CspZ is a distinct protein encoded by the $\operatorname{csp} Z$ gene located on plasmid $1 \mathrm{p} 28-3$ and is expressed at higher levels during the mammalian infection than in bacteria residing in ticks or during laboratory cultivation [18]. Anti-CspZ antibodies can be detected as early as two weeks post infection in mice infected by ticks [20]. CspZ has been shown to bind other yet unknown proteins and therefore can have multiple functions [19-22]. The CFH-binding CRASP proteins BbCRASP-3, -4 , and -5 belong to the OspErelated proteins (Erp) paralogous family and their respective genes are located on diverse cp32 prophage DNA molecules [23]. Erp proteins are expressed in tissues in the host during disseminated mammalian infection. Erp proteins have also been shown to be able to bind to factor $\mathrm{H}$ related proteins-1 (CFHR1) and plasminogen [24-29].

In contrast to B. burgdorferi ss and B. afzelii most $B$. garinii strains are unable to bind human complement regulators [30]. Two CspA orthologs from B. garinii ST6 ZQ1, named BgCRASP- $1 \alpha$ and BgCRASP- $1 \beta$, have been shown to bind weakly to FHL-1 but not to human CFH [31]. Little data is published on complement evasion strategies of human serum resistant strains of the B. garinii ST4 strains. The gbb54 orthologous family of B. garinii ST4 has not been studied before.

It has been elaborately shown which gbb54 ortholog from B. burgdorferi ss and B. afzelii can bind human $\mathrm{CFH}$, but little is known about the function of the other orthologs. It has been described previously that CspA derived from $B$. burgdorferi ss interacts with human $\mathrm{CFH}$; however none of the closely related protein of the gbb54 family, interacts with human CFH [32]. Wallich et al characterised all gbb54 orthologous members of a B. afzelii and B. garinii strain wherein none of the remaining orthologs could bind human CFH/FHL-1 $[17,31]$. We hypothesise that orthologs from the gbb54 family have the ability to bind to CFH from several animal origins.

The aim of the present study was to investigate the mechanism for complement evasion by B. garinii ST4 strains and to isolate and functionally characterize the specific gbb54 orthologs binding to human CFH/FHL-1 and also to other mammalian and avian $\mathrm{CFH}$. We could prove binding of $2 \mathrm{ST} 4 \mathrm{gbb}$ orthologs, BGA66 and BGA71, to human FHL-1, whereas BGA66 also bound $\mathrm{CFH}$. Moreover, both these and other orthologs from the gbb54 family were also able to bind CFH from various animal species.

\section{Results}

\section{Serum susceptibility testing of borrelial strains}

To assess and to compare serum susceptibility of B. garinii $\mathrm{PBi}$ and VSBP as well as B. burgdorferi ss B31, spirochetes were incubated for $3 \mathrm{~h}$ with either $50 \%$ NHS or $50 \%$ HI NHS. As shown in Fig $1,>75 \%$ of the cells of $B$. garinii ST4 PBi and B. burgdorferi ss B31 survived in serum, indicating that both strains resist complementmediated killing. In contrast, B. garinii non-ST4 strain VSBP was highly sensitive to complement as $99 \%$ of the cells were immobilized and showed blebs after 3 hours. Incubation of strains PBi, VSBP, and B31 with HI NHS resulted in no or very little immobilisation. Summarising B. garinii ST4 PBi and B. burgdorferi ss B31 are resistant to human serum when incubated with active human complement, while B. garinii non-ST4 VSBP is not human serum resistant.

\section{The detection of the membrane attack complex} deposited on borrelial cells after complement activation

To test whether membrane attack complex (MAC) was formed on the surface of different strains after complement activation, spirochetes were incubated with $25 \%$ serum and deposition of the MAC was detected by immuno-fluorescence microscopy (IF) (Fig 2). The majority of the cells of B. garinii ST4 PBi and $B$. burgdorferi ss B31 stained negative for the MAC while all B. garinii non-ST4 VSBP were fully covered with MAC. This finding indicates that B. garinii ST4 $\mathrm{PBi}$ and B. burgdorferi ss B31 allow formation of the MAC on their bacterial surface only to a limited extent in comparison to B. garinii non-ST4 strain VSBP. 


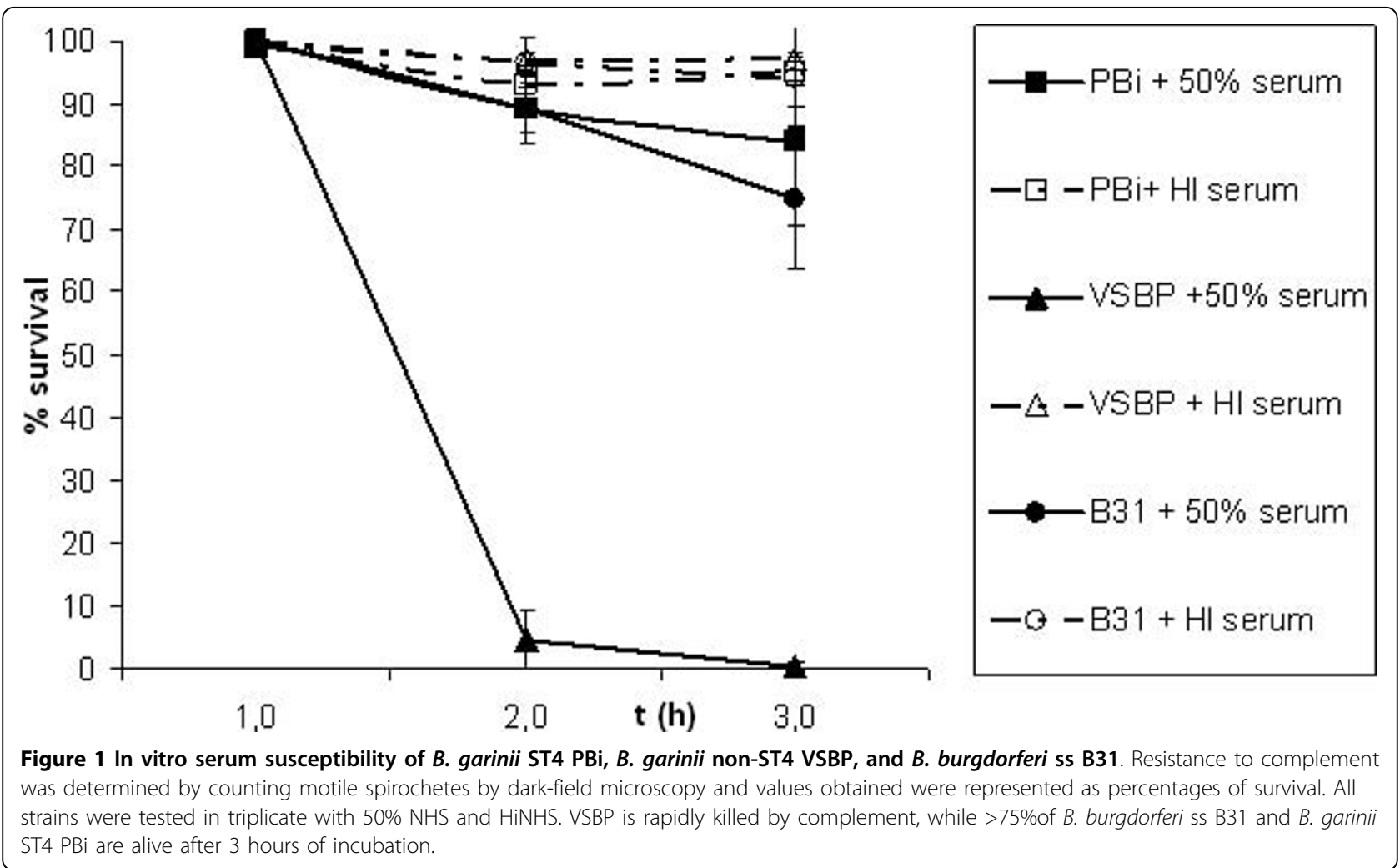

\section{Detection of bound complement regulators to different borrelial strains}

In order to elucidate the capability of serum resistant $B$. garinii ST4 PBi to bind complement regulators $\mathrm{CFH}$ and FHL-1 to the surfaces in a non-denatured state, intact spirochetes were incubated with NHS which was supplemented with EDTA to prevent complement activation. Complement regulators were allowed to adsorb to the Borrelia surface and bound proteins were subsequently eluted with acidified $0.1 \mathrm{M}$ glycine. The wash and the eluate fraction were analyzed for the presence of CFH and FHL-1 by Western blotting. As shown in Fig 3, FHL-1, but not CFH could be detected in the eluate fraction indicating that $B$. garinii ST4 PBi specifically interact with FHL-1.

\section{Accessibility and surface exposure of $\mathrm{CFH} / \mathrm{FHL}-1$ binding proteins of $B$. garinii ST4 PBi}

In order to identify FHL-1 binding proteins produced by B. garinii ST4 PBi and to determine whether these proteins are exposed to the extracellular space, spirochetes were treated with increasing concentrations of proteinase $\mathrm{K}$ or trypsin and proteolysis was detected by ligand affinity blotting. Cell lysates obtained after protease treatment were separated by SDS-PAGE, transferred to nitrocellulose and the respective proteins were detected. As shown in Fig 4, four distinct binding proteins could be detected in untreated serum-resistant $B$. garinii ST4 $\mathrm{PBi}$. Treatment with proteinase $\mathrm{K}$ at the lowest concentration resulted in the complete elimination of $\mathrm{CFH} /$ FHL-1 binding. Upon treatment with trypsin, degradation was only achieved at a concentration of $100 \mu \mathrm{g} / \mu \mathrm{l}$. As expected, the intracellular protein flagellin was resistant to trypsin and proteinase $\mathrm{K}$ treatment, even at the highest concentration. These data demonstrate that $B$. garinii ST4 PBi produced up to four surface-exposed CFH/FHL-1 binding proteins, in the range of 19-26 $\mathrm{kDa}$. This is in concordance to the findings of McDowell et al, where B. garinii ST4 PBi expressed a 20.5 and $26 \mathrm{kDa}$ protein that were found to interact with $\mathrm{CFH}$ [33]. The CspA orthologs tested in this study are in the range of 25-27 $\mathrm{kDa}$, the smaller proteins detected appear to belong to the Erp protein family.

\section{Cloning and identification of the CFH/FHL-1 binding proteins of $B$. garinii ST4 PBi}

Assuming that the genes encoding CFH/FHL-1 binding proteins of $B$. garinii ST4 PBi share similarity to CspA encoding cspA gene of $B$. burgdorferi ss $\mathrm{B} 31, B$. afzelii MMS and B. garinii ZQ1, a database search was conducted. Four genes revealed a high degree of similarity with either CspA of B. burgdorferi ss B31, B. afzelii MMS or B. garinii ZQ1 as described previously [31,34]. BGA66, BGA67, BGA68 and BGA71 showed similarity 


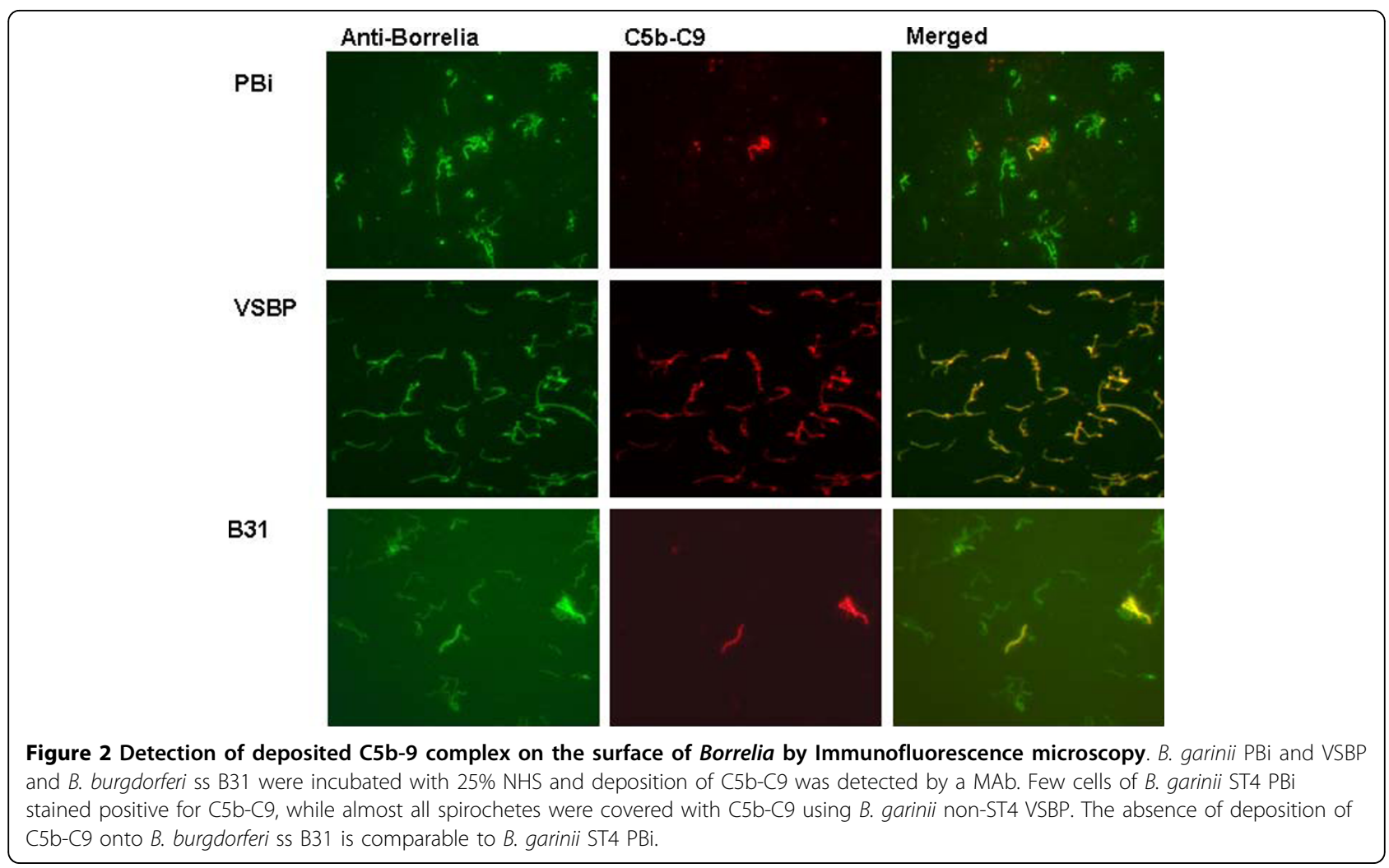

to previously described CspA of about $50 \%$. Comparative sequence analysis, revealed that orthologs BGA66 and BGA71 were found to have the highest degree of similarity within the putative CFH/FHL-1 binding regions of CspA (region 1-3)[35-37]. BGA66, BGA67, BGA68 and BGA 71 as well as CspA of B. burgdorferi ss strain B31 were cloned and expressed as GST fusion proteins.

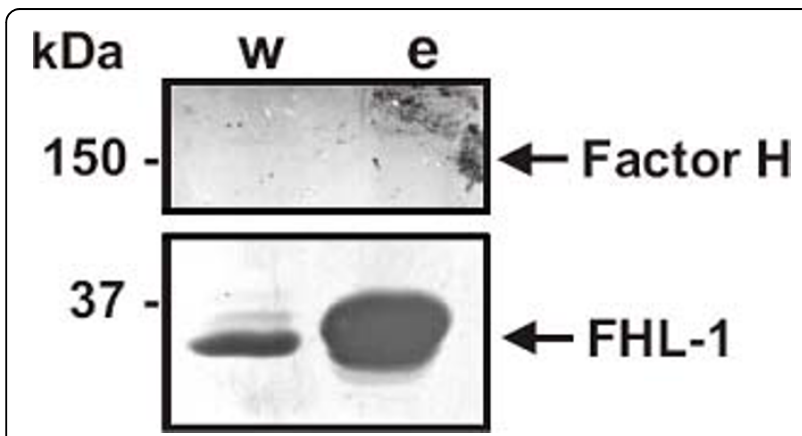

Figure 3 Detection of bound complement regulators by $B$. garinii ST4 PBi. After incubation of spirochetes with NHS-EDTA, bound proteins were eluted. The wash ( $w$ ) and the eluate (e) fraction were separated by SDS-PAGE. The last wash and eluate fraction were subjected to SDS-PAGE and separated proteins were blotted on nitrocellulose. $\mathrm{CFH}$ and $\mathrm{FHL}-1$ were visualised using a polyclonal goat anti-factor CFH antiserum (Calbiochem). It is shown that $\mathrm{B}$. garinii ST4 PBi is able to bind FHL-1 on its membrane.

\section{Determination of binding of CspA orthologs to CFH and} FHL-1

Binding of CFH and FHL-1 to non-denatured purified recombinant proteins was evaluated by ligand affinity blot. Proteins were separated under denaturing conditions and subsequently blotted on a nitrocellulose membrane. As shown in Fig 5, BbCspA used as positive control bound strongly to $\mathrm{CFH}$ and FHL-1 as described previously [34]. Orthologs BGA66 and BGA71 were capable of binding to both complement regulators, however, with reduced intensities compared to CspA.

To further confirm binding of CspA orthologs an ELISA was conducted. CspA orthologs BGA66, BGA67, BGA68, and BGA71 were immobilized on a microtiter plate and binding of CFH and FHL-1 was evaluated (Fig 6). BbCRASP-1 used as a positive control strongly bound to CFH and FHL-1. Of the four CspA orthologs analyzed, BGA66 was capable of binding to both complement regulators, this binding was significantly higher than the baseline $(\mathrm{p}<0.05)$. Ortholog BGA71 specifically bound to FHL-1 ( $p<0.05)$ but less efficiently than CspA and BGA66. In contrast, orthologs BGA67 and BGA68 were not able to bind to CFH or FHL-1 at all.

These data confirmed that orthologs BGA66 as well as BGA71 derived from B. garinii ST4 PBi were capable of binding FHL-1. Binding of $\mathrm{CFH}$ in both assays is evident for BGA66, but not for BGA71. 


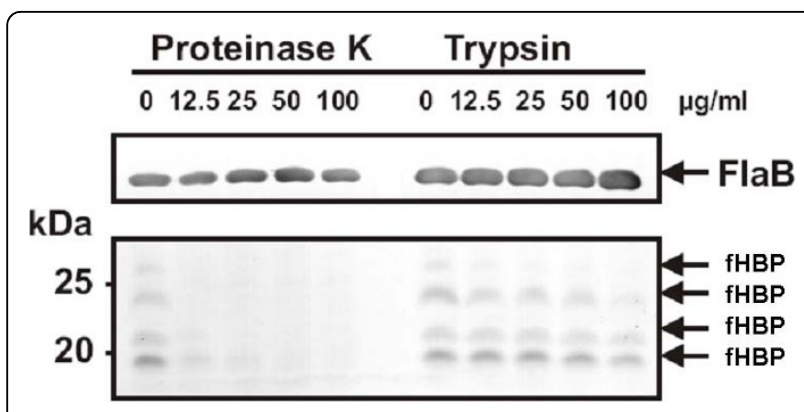

Figure 4 Accessibility of CFH/FHL-1 binding proteins of $B$. garinii ST4 PBi by different proteases. Spirochetes of $B$. garinii ST4 PBi were incubated with either proteinase $K$ or trypsin at concentrations of 12.5 to $100 \mu \mathrm{g} / \mathrm{ml}$ or in buffer without any protease (0). After $1 \mathrm{~h}$ of incubation, cells were lysed by sonication as described in Materials and Methods. Each protein lysate was then subjected to $10 \%$ Tris/Tricine SDS-PAGE, blotted to membranes, and analyzed by Western or ligand affinity blotting. $\mathrm{CFH} / \mathrm{FHL}-1$ binding proteins were identified using NHS and a polyclonal anti-CFH antibody. Equal sample loading was assessed by detection of flagellin (FlaB) using MAb L41 1C11 1C11 at a dilution of 1:1000. Mobilities of molecular mass standards are indicated to the left. Four proteins able to bind $\mathrm{CFH} / \mathrm{FHL}-1$ and they are readily digested by proteinases and therefore located on the membrane.

\section{Mapping of the binding domains of $\mathrm{CFH}$ and FHL-1 to CspA orthologs}

In order to map the binding regions of $\mathrm{CFH}$ and FHL-1 interacting with BGA66 and BGA71, various deletion constructs of CFH and FHL-1 were used for ligand affinity assays (Fig 7). BGA66 bound to full-length CFH and FHL1 , but to none of the deletion constructs lacking SCRs 5-7. BGA71 bound FHL-1 as well as deletion constructs SCR15 and SCR1-6. Thus, SCR5-7 of both CFH and FHL-1 are required for binding to BGA66 and BGA71.

Expression of BGA66 and BGA71 by real-time RT-PCR CDNA prepared from in vitro cultured B. garinii ST4 $\mathrm{PBi}$ were tested in a quantitative real time PCR. Cultures repeated in sexplet demonstrated a mean expression of BGA66 of 34 copies/1000 copies flaB (SD 22) and BGA71 21 copies/1000 copies flaB (SD 18). All spirochetes cultivated in vitro expressed BGA66 and BGA71 simultaneously.

\section{Analysis of CFH binding of different animal sera to CspA orthologs}

A variety of sera obtained from different animals were used to analyse binding of CFH to CspA, BGA66, BGA67, BGA68, and BGA71 by ligand affinity blotting. As shown in Fig 8, CspA orthologs displayed distinct capacity of binding to $\mathrm{CFH}$ from a wide variety of sera from different mammals and poultry. All orthologs exhibit binding of $\mathrm{CFH}$ from bovine, equine and canine serum with different intensities. BGA68 and BGA71 showed a weak binding capacity to murine CFH. In addition, BGA68 but not CspA nor other orthologs bound to avian $\mathrm{CFH}$. Porcine and feline serum proteins did not bind any of the CspA orthologs of B. garinii ST4 PBi while feline CFH appears to bind only to BbCspA.

\section{Discussion}

We are the first to demonstrate that B. garinii ST4 PBi is serum resistant and is able to acquire FHL-1 but not CFH from human serum. In addition, we identified two distinct CspA orthologs, BGA66 and BGA71 as potential ligands of complement regulators CFH and FHL-1. These proteins were produced under in vitro conditions as demonstrated by real time PCR. Finally, we demonstrated distinct binding capacities of $\mathrm{CFH}$ of different mammalian and avian origin to different CspA orthologs of serum resistant B. garinii ST4 PBi.

In Europe four human pathogenic genospecies are endemic. B. burgdorferi ss, $B$. afzelii, and B. spielmanii display a human serum resistant phenotype while $B$.

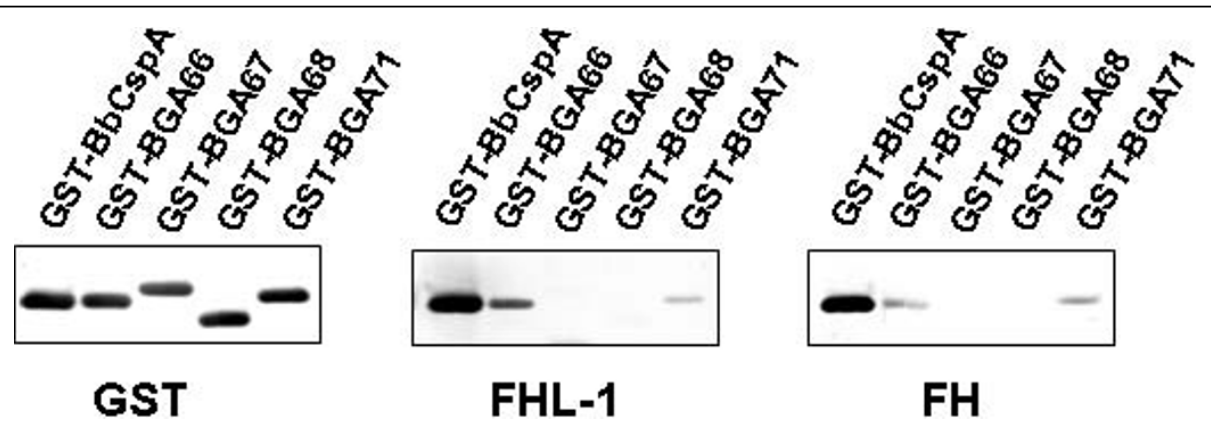

Figure 5 Binding capabilities of CFH and FHL-1 to CspA orthologs of B. garinii ST4. Purified GST fusion proteins, BbCspA, BGA66, BGA67, BGA69, and BGA71 (500 ng/lane) were subjected to 10\% Tris/Tricine SDS-PAGE and blotted to nitrocellulose membranes. Membranes were then incubated with recombinant FHL-1 or with NHS. GST-fusion proteins were detected by using anti-goat GST antibody and binding to CFH and FHL-1 were visualized using mAb VIG8 specific for the C-terminal region of CFH and $\alpha$ SCR1-4 antiserum specific for the N-terminal region of FHL-1. Binding of CFH and FHL-1 is visible for BGA66 and BGA71. 

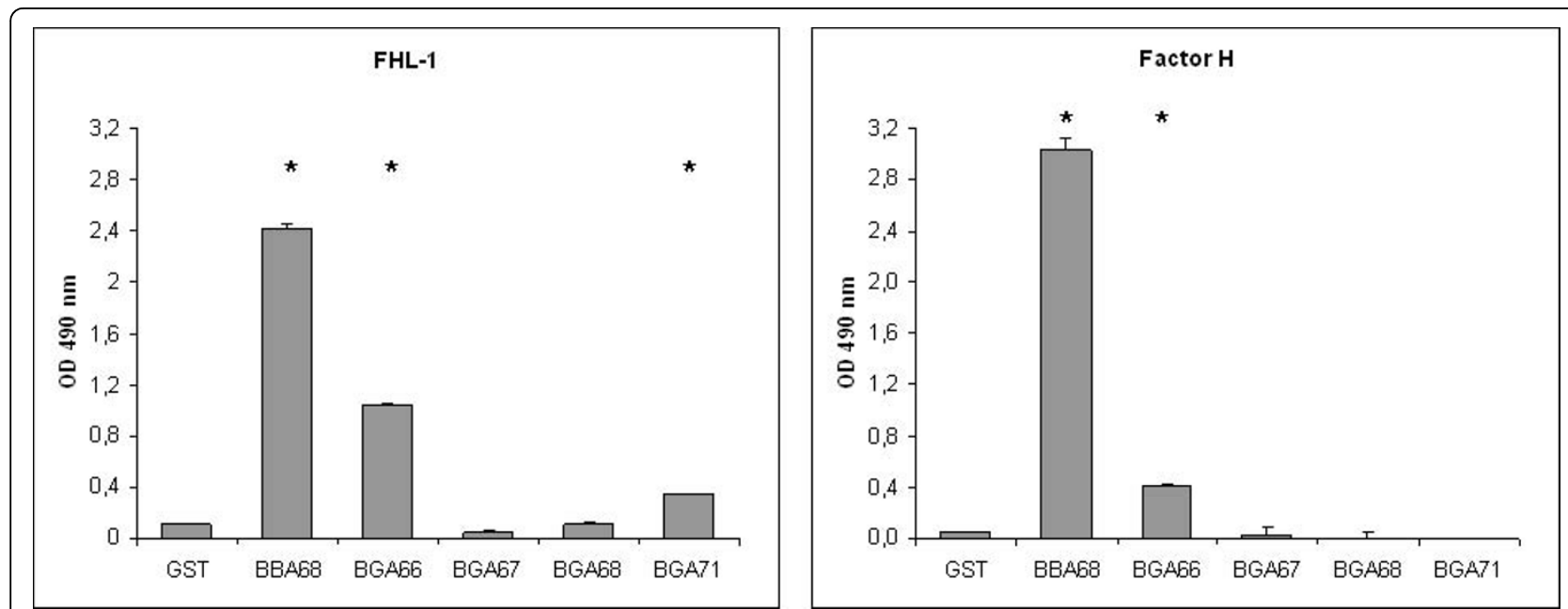

Figure 6 Binding of CspA orthologs to FHL-1 and CFH. Recombinant proteins (500 ng each) were coated onto an ELISA plate and incubated with purified FHL-1 (A) and CFH (B). Binding was assayed by ELISA using polyclonal $\alpha$ SCR1-4 that recognized CFH and FHL-1. All experiments were performed at least in triplicate. ${ }^{*}(p<0.05$ compared to baseline (GST) OD)

garinii strains are often serum sensitive [8-10,38,39]. Within the OspA typing scheme, B. garinii ST4 strains represent a distinct branch as shown by random amplified polymorphic DNA (RAPD) analysis. On the basis of MLSA analysis it has recently been proposed, though not yet generally accepted, to delineate this subgroup in a separate species; $B$. bavariensis $[7,40]$. B. garinii ST4 is remarkably often associated with dissemination to the CNS $[3,5,6,41]$. In a previous study it was confirmed that B. garinii non-ST4 strains, including strains isolated from CSF, are sensitive to complement while B. garinii ST4 strains were resistant to human complement [10]. In this report we confirm with an in vitro killing assay and IF that B. garinii ST4 is resistant to human complement killing and that it does not allow formation of MAC on the spirochetal membrane.

It has been extensively shown that CspA fulfils a key role in complement resistance of B. burgdorferi ss $[42,43]$. In the present study, a comparative binding analysis was conducted to isolate and characterize CspA

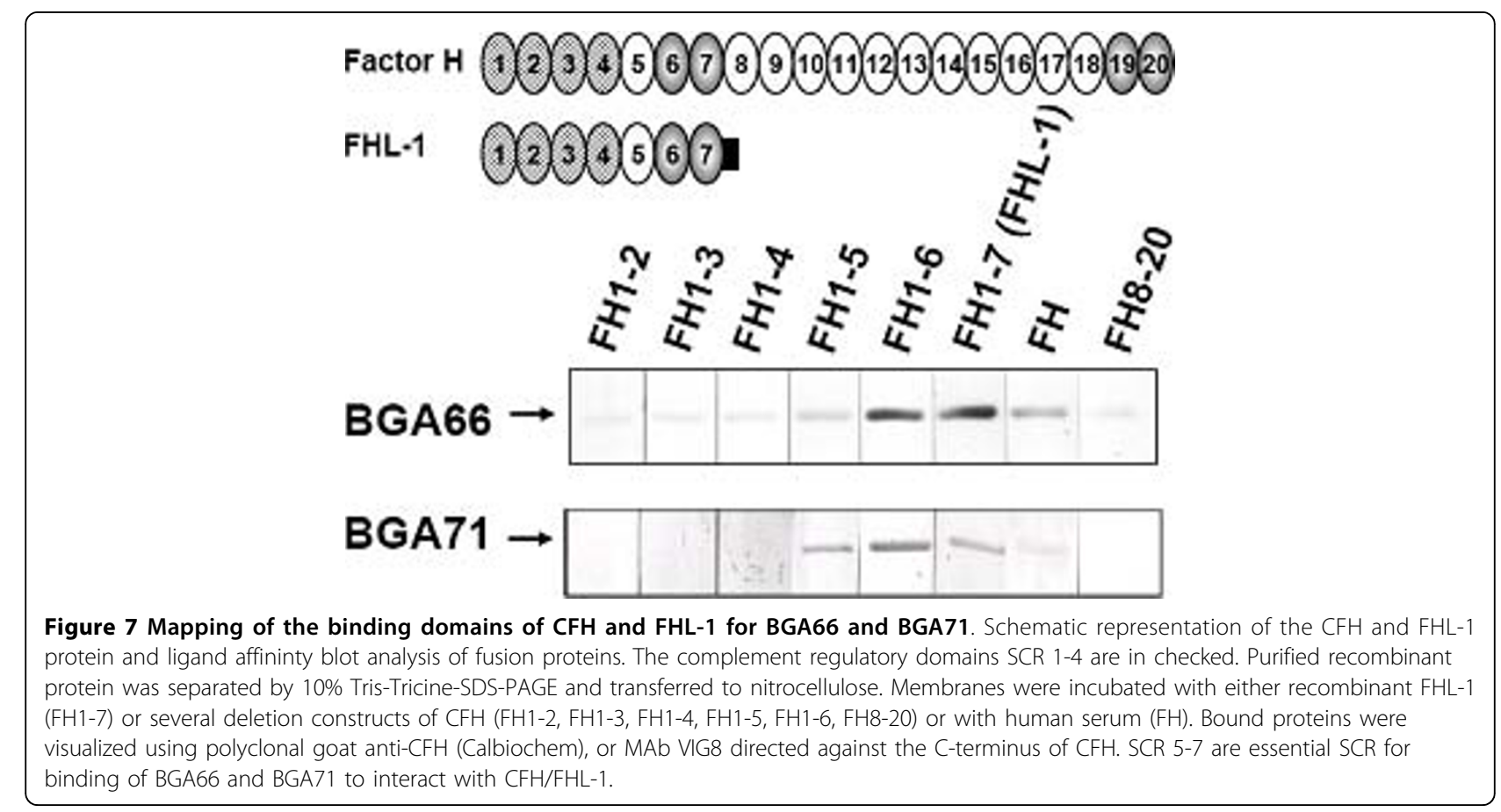


orthologs from the serum resistant, $B$. garinii ST4 strain $\mathrm{PBi}$. We hypothesised that binding of $\mathrm{CFH}$ and/or FHL1 via CspA orthologs contributes to serum resistance of B. garinii ST4 PBi. We identified orthologs BGA66 and BGA71 but not BGA67 and BGA68 as being potential ligands for FHL-1 and CFH. In vitro cultured spirochetes bound FHL-1 but not CFH on their surface. The affinity for FHL-1 appeared to be stronger than for $\mathrm{CFH}$, it can be concluded that FHL-1 competes with $\mathrm{CFH}$ for the same binding site and thus CFH could not be detected in the cell binding assay. When employing ELISA on recombinant proteins, BGA66 bound both complement regulators while BGA71 only bound FHL1. By ligand affinity blotting BGA71 bound FHL-1 as well as CFH. A logical explanation for this phenomenon might be the denaturing conditions of the Western blot, suggesting that native BGA71 specifically interacts with FHL-1 only.

Furthermore, it was previously shown that CspA forms homodimers and three regions of CspA have been implicated in formation of a functional binding site of CspA to CFH/FHL-1 [35-37,43]. Previously it has been hypothesised that the C-terminal YKXXDXXXP motif is important in binding of CFH and FHL-1, as well as the lysine residue at position 246 of CspA [31]. Recently it was also shown that a leucine residue at position 146 within the proposed $\mathrm{CFH}$ binding region 1 as well as Tyr240, Asp242 and Leu246 within the proposed binding region 3 of CspA were important in binding of CFH and FHL-1 [35]. The C-terminus of all known human CFH/FHL-1 binding CspA and the $B$. garinii ST4 gbb54 orthologs is shown in table 1. Comparative sequence analysis revealed that the $\mathrm{C}$-terminus of BGA66 and BGA71 are highly homologous to the Cterminus of all known human CFH/FHL-1 binding CspA. Ortholog BGA66 contains the C-terminal motif as well as the Leu246, while BGA71 contains the Cterminal motif but has a phenylalanine instead of a leucine residue at position 246. Positions 146 and 240 are unchanged in BGA66 and BGA71 both orthologs show substitutions at position 242; the Asp242 in BGA66 and BGA71 is replaced by a glutamic acid and a threonine residue, respectively. A substitution of Asp242 by a neutral alanine residue within CspA did not have a significant effect on binding, while the replacement of aspartic acid by tyrosine at this position influenced binding of FHL-1 and is associated with a loss of binding of CFH [35]. Lack of binding of native BGA71 to CFH is likely to be due to the non-synonymous mutation of aspartic acid by threonine, while BGA66 can still bind both CFH and FHL-1 due to the synonymous mutation of aspartic acid to glutamic acid. It is likely that absence of $\mathrm{CFH}$ binding by BGA71 might be a result of an effect of the mutation on protein folding and conformation. Our finding that under denaturing conditions BGA71 can bind $\mathrm{CFH}$, but not under native folded conditions supports this hypothesis.

A number of Gram-negative as well as Gram-positive bacteria have already been shown to be able to bind $\mathrm{CFH}$ in order to protect themselves from complementmediated lysis [44-46]. CFH possess three binding sites for complement C3b, however the only essential binding site is SCR1-4 $[12,47,48]$. Here we show that BGA66 as well as BGA71 bind SCR5-7 of CFH and FHL-1, thus leaving the $\mathrm{N}$-terminus free for maintaining their regulatory activity in factor I-mediated inactivation of $\mathrm{C} 3 \mathrm{~b}$ [34]. Our finding indicates that B. garinii ST4 strains can bind functionally active CFH and FHL-1 on the membrane by BGA66 and BGA71 in order to evade complement activation.

B. burgdorferi sl has developed an intriguing system to respond to changes of the microenvironments by coordinated expression of proteins. In vitro experiments usually do not completely mirror the expression patterns of CspA during the tick to mammal infectious cycle and might also vary in cultured population [49]. CspA shows a distinct expression profile as it is mainly expressed during transmission of spirochetes from the tick-tomammal and mammal-to-tick infection cycle [19]. Previously antibodies to CspA could be detected in sera from infected mice and from Lyme disease patients suggesting prolonged expression of CspA in the mammalian host [50-52]. In the present study we demonstrated that in vitro $B$. garinii $\mathrm{ST} 4 \mathrm{PBi}$ is capable of expressing BGA66 and BGA71. Experiments regarding expression of BGA66 and BGA71 during tick-to-mammal transmission and mammalian infection are ongoing and will give more insight in their function in vivo.

Although all five CRASPs of B. burgdorferi sl are primarily identified as ligands of human complement regulators, several studies clearly showed that CspA can also bind CFH from other mammalian hosts [22]. CFH binding of several animal CFH sources has also been reported in a recent article where new $\mathrm{CFH}$ binding proteins were identified [53]. It is still not quite clear how the wide variety of complement resistance is obtained in strains that do not interact with human $\mathrm{CFH}$. The B. burgdorferi ss and B. afzelii orthologs of CspA were previously not studied for binding to $\mathrm{CFH}$ of non-human origin. In this study all CspA orthologs of B. garinii ST4 PBi were tested with whole sera from different animals. BGA67 and BGA68 lack binding to human $\mathrm{CFH}$ but were able to interact with $\mathrm{CFH}$ from other hosts, of which some are not competent reservoir hosts for Borrelia. It is likely that several members of the gbb54 paralogous family are designated to bind CFH from other species in the infectious cycle and are therefore not redundant but essential for infection of a wide 


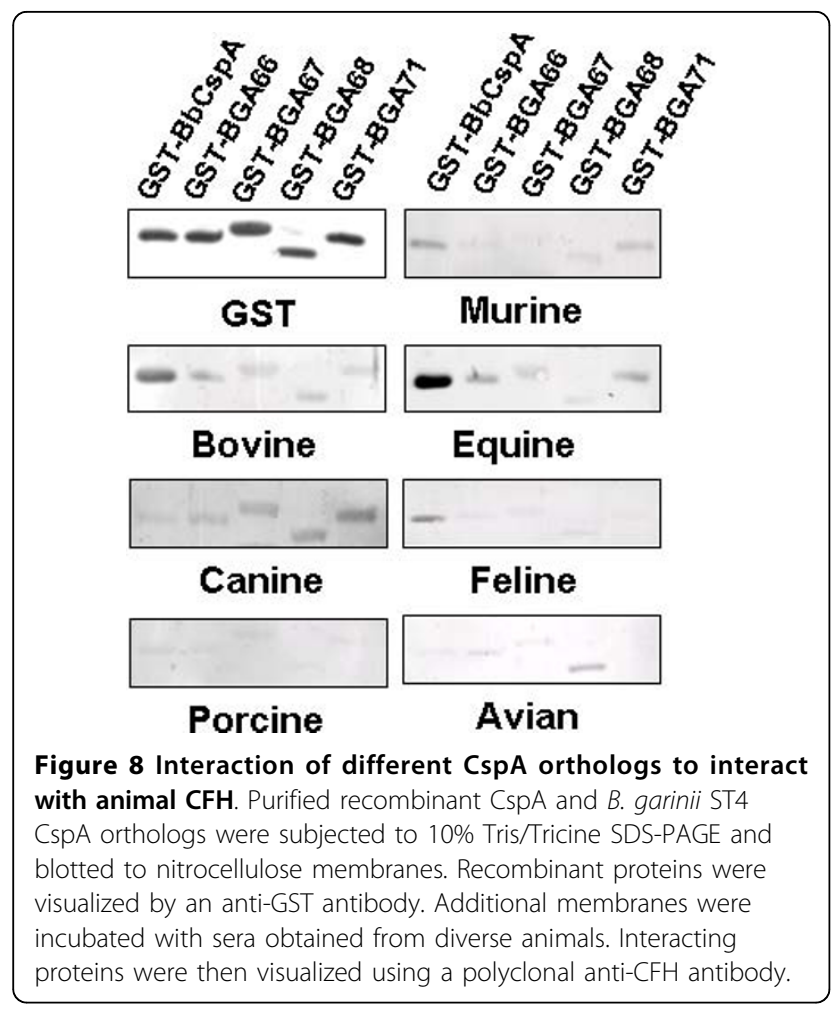

range of hosts. The interaction of mammalian $\mathrm{CFH}$ with CspA orthologs of B. burgdorferi sl might unveil a part of the serum resistance patterns obtained from in vitro experiments.

\section{Conclusions}

In this study we demonstrated B. garinii ST4 PBi is able to evade complement killing and it can bind FHL-1 to membrane expressed proteins. Recombinant proteins BGA66 can bind FHL-1 and human CFH, while BGA71 can bind only FHL-1. All recombinant CspA orthologs from $\mathrm{PBi}$ can bind $\mathrm{CFH}$ from different animal origins.

Table 1 C-terminus of all CspA and B. garinii ST4 CspA orthologs

\begin{tabular}{|c|c|c|c|c|c|c|c|c|c|c|c|c|c|}
\hline \multicolumn{2}{|l|}{ Protein } & \multicolumn{10}{|c|}{240} & \multicolumn{2}{|c|}{250} \\
\hline $\mathrm{BbCspA}$ & $Y$ & $Y$ & $\mathrm{~K}$ & $D$ & $F$ & $D$ & $\mathrm{~T}$ & $L$ & K & $P$ & $A$ & $F$ & Y \\
\hline $\mathrm{BaCspA}$ & $\mathrm{N}$ & $Y$ & $\mathrm{~K}$ & $D$ & $L$ & $\mathrm{D}$ & S & $F$ & $\mathrm{~N}$ & $P$ & 1 & $N$ & - \\
\hline $\mathrm{BgCspA \alpha}$ & $\mathrm{N}$ & $Y$ & $\mathrm{~K}$ & $E$ & $\mathrm{~F}$ & D & $P$ & $L$ & $\mathrm{~N}$ & $L$ & D & $Y$ & - \\
\hline $\mathrm{BgCspA} \beta$ & $\mathrm{N}$ & $\mathrm{Y}$ & $\mathrm{K}$ & $T$ & $\mathrm{~L}$ & D & S & $F$ & K & $S$ & I & $\mathrm{N}$ & - \\
\hline BGA66 & $\mathrm{N}$ & $Y$ & $\mathrm{~K}$ & $E$ & $H$ & D & S & $L$ & K & $P$ & 1 & $Y$ & - \\
\hline BGA67 & $\mathrm{N}$ & $Y$ & $\mathrm{~K}$ & $E$ & $\mathrm{~F}$ & $N$ & S & $L$ & K & $P$ & 1 & $Y$ & - \\
\hline BGA68 & $\mathrm{N}$ & $Y$ & $\mathrm{~K}$ & $N$ & $L$ & $\mathrm{H}$ & S & $F$ & K & $\mathrm{T}$ & V & $Y$ & Y \\
\hline BGA71 & $\mathrm{N}$ & $Y$ & $\mathrm{~K}$ & $T$ & $L$ & D & S & $F$ & K & $P$ & I & $\mathrm{N}$ & - \\
\hline
\end{tabular}

C-terminal end of CspA orthologs described in this study and previously determined. Positions 242 and 246 depicted in italic. The sequence for CspA derived from $B$. burgdorferi ss B31, BaCspA from B. afzelii MMS, ZQA68 $(\mathrm{BgCspA} \alpha)$ and ZQA71 (BgCspA $\beta$ ) from B. garinii ZQ1, BGA66, BGA67, BGA68 and BGA71 from B. garinii ST4 PBi.
This can partly explain the wide variety of animals that B. garinii can infect.

\section{Methods}

Borrelial strains and culture conditions

B. garinii strains PBi and VSBP as well as B. burgdorferi ss strain B31 were cultured until mid-log phase $\left(5 \times 10^{7}\right.$ cells per $\mathrm{ml}$ ) at $33^{\circ} \mathrm{C}$ in modified Barbour-StoennerKelly (BSK-H) medium (Sigma). Aliquots of $1 \mathrm{ml}$ were then diluted 1:1 with glycerol peptone (8\% glycerol, $1 \%$ w/v Proteose Peptone 3 (Brunschwig chemie, Amsterdam) in distilled water), dispensed into screw-cap tubes (Nunc, Wiesbaden, Germany), frozen at $-80^{\circ} \mathrm{C}$, and used as stock cultures. Prior to use, a frozen suspension of spirochetes was thawed and inoculated into fresh BSK$\mathrm{H}$ medium.

\section{Serum bactericidal assay}

Serum susceptibility of Borrelia was determined as described previously [10]. Briefly, serum obtained from a non-immune human donor (NHS) was frozen at $-80^{\circ} \mathrm{C}$ and thawed on ice prior to use. Heat inactivated (HI) serum was incubated for 1 hour at $56^{\circ} \mathrm{C}$ in order to inactivate complement. B. garinii $\mathrm{ST} 4 \mathrm{PBi}, B$. garinii non-ST4 VSBP, and B. burgdorferi ss B31 were cultured until mid-log phase in BSK-H. An aliquot of $50 \mu \mathrm{l}$ containing $10^{7}$ live Borrelia $/ \mathrm{ml}$ was added to $50 \mu \mathrm{l}$ of serum and incubated for 1 and $3 \mathrm{~h}$ at $33^{\circ} \mathrm{C}$. After incubation aliquots of $5 \mu \mathrm{l}$ were drawn from the suspensions and mobility and blebbing of the spirochetes was assessed under dark-field microscopy. One hundred spirochetes were examined, motile cells as well as non-motile cells were counted and the percentage of survival was calculated. The experiment was repeated three times.

\section{Immunofluorescence assay}

Immunofluorescence microscopy was performed as described previously [54].

Briefly, freshly cultured B. garinii strains PBi, VSBP, and $B$. burgdorferi ss B31 were incubated for 30 minutes in BSK-H medium containing 25\% NHS. Subsequently spirochetes were washed twice with $\mathrm{PBS} / 1 \% \mathrm{BSA}$, resuspended in the same buffer and air dried on microscope slides overnight. After fixation in $100 \%$ methanol, slides were incubated with human immune serum containing anti-Borrelia antibodies (1:2000) and a mAb recognizing a neoepitope of the terminal C5b-9 complex (1:1000) (DAKO). Slides were washed with PBS-1\% BSA and incubated with an anti-human immunoglobulin G-fluorescein isothiocyanate-labeled antibody (1:100) (bioMérieux) and an anti-mouse immunoglobulin G Cy3-labeled antibody (1:1000) (Jackson). Afterwards slides were washed three times and mounted with Mowiol (Hoechst). Spirochetes were visualized by confocal 
microscopy using an Axioscop 2 mot plus fluorescence microscope (Carl Zeiss).

\section{Serum adsorption experiments}

Borrelia $\left(2 \times 10^{9}\right.$ cells $)$ were grown to mid-log phase, harvested by centrifugation $\left(5,000 \times g, 30 \mathrm{~min}, 4^{\circ} \mathrm{C}\right)$, and resuspended in $100 \mu \mathrm{l}$ of veronal-buffered saline (supplemented with $1 \mathrm{mM} \mathrm{Mg}{ }^{2+}-0.15 \mathrm{mM} \mathrm{Ca}^{2+}-0.1 \%$ gelatine, $\mathrm{pH}$ 7.4). To inhibit complement activation, NHS was incubated with $0.34 \mathrm{mM}$ EDTA for $15 \mathrm{~min}$ at room temperature. The spirochete suspension was then incubated in $1.5 \mathrm{ml}$ of NHS-EDTA for 1 hour at room temperature with gentle agitation. After three washes with phosphate-buffered saline (PBS) (supplemented with.15 $\mathrm{M} \mathrm{NaCl}, 0.03 \mathrm{M}$ phosphate, $0.02 \%$ sodium azide, $\mathrm{pH}$ 7.2), $0.05 \%$ Tween 20 . The proteins bound to the cells were eluted by incubation with $0.1 \mathrm{M}$ glycine- $\mathrm{HCl}, \mathrm{pH}$ 2.0, for $15 \mathrm{~min}$. Cells were removed by centrifugation at $14,000 \times g$ for $20 \mathrm{~min}$ at $4{ }^{\circ} \mathrm{C}$, and supernatants were then analysed by Western blotting.

\section{Protease degradation assay}

To characterize protease-susceptibility of $\mathrm{CFH}$ and FHL1 binding proteins of $B$. garinii ST4 PBi, cells were treated with two different proteases as described previously [34]. Briefly, spirochetes were grown to mid-log phase, sedimented by centrifugation at $5,000 \times \mathrm{g}$ for $30 \mathrm{~min}$, washed twice with cold PBS containing $5 \mathrm{mM} \mathrm{MgCl}$ (PBS-Mg), and resuspended in $100 \mu \mathrm{l} \mathrm{PBS}-\mathrm{Mg}$. To the Borrelia cell suspension (at a concentration of $10^{8}$ in a final volume of $0.5 \mathrm{ml}$ ), proteinase $\mathrm{K}$ or trypsin was added to a final concentration of $12,5 \mu \mathrm{g} / \mathrm{ml}$ to $100 \mu \mathrm{g} /$ $\mathrm{ml}$. Following incubation for 1 hour at room temperature, proteolytic degradation with proteinase $\mathrm{K}$ or trypsin was terminated by the addition of $5 \mu \mathrm{l}$ of phenylmethylsulfonyl fluoride or by the addition of $5 \mu \mathrm{l}$ of phenylmethylsulfonyl fluoride and $5 \mu \mathrm{l}$ of 4-(2-aminoethyl)-benzenesulfonyl fluoride, respectively. Borrelia were then gently washed twice with $\mathrm{PBS}-\mathrm{Mg}$, resuspended in $20 \mu \mathrm{l}$ PBS-Mg, and lysed by sonication five times using a Branson B-12 sonifier (Heinemann, Schwäbisch Gmünd, Germany). Equal volumes of Borrelia lysates were subjected to Tris/Tricine SDS-PAGE, and proteins were transferred to nitrocellulose membranes as described previously [16]. Susceptibility of proteins to proteolytic degradation was assessed by Western or ligand affinity blotting with the appropriate monoclonal or polyclonal antibodies, followed by incubation with a horseradish peroxidase-conjugated IgG antibody, and then visualized by the addition of 3, 3', 5, 5'-tetramethylbenzidine.

\section{PCR cloning, expression and purification of recombinant CspA orthologous proteins}

Sequences of genes encoding for CspA B31 and orthologs from B. garinii ST4 PBi were obtained from genbank (NC_006129 and NC_001857). Primers were designed using primer3 (MIT) and listed in table 2. Amplification reactions were performed in a $50 \mu$ final volume, containing $25 \mu \mathrm{l}$ IQ Supermix (Bio-Rad, Veenendaal, The Netherlands), 15 pmol forward primer, 15 pmol reverse primer, and $10 \mu \mathrm{l}$ of a DNA isolate of cultured B31 or PBi. Following an enzyme activation step for $3 \mathrm{~min}$ at $95^{\circ} \mathrm{C}$, amplification comprised 50 cycles of $30 \mathrm{~s}$ at $95^{\circ} \mathrm{C}, 30 \mathrm{~s}$ at $55^{\circ} \mathrm{C}$ and $30 \mathrm{~s}$ at $72^{\circ} \mathrm{C}$. Genes lacking their leader sequences were ligated in frame into the pGEX-5X3 vector (Amersham

Table 2 Oligonucleotides used in this study

\begin{tabular}{|c|c|c|}
\hline Oligonucleotides & Sequence $\left(5^{\prime}-3^{\prime}\right)$ & Target \\
\hline BBA68s & ATGCGGCCGTGTTGTGTTTAATTTGGAT & BBA68 \\
\hline BBA68as & GTGGGATCCCATGCGCACCTITTAGCAA & BBA68 \\
\hline BGA66s & ATGCGGCCGTGTTITTAGTTTGGGCTCT & BGA66 \\
\hline BGA66as & GTGGGATCCCATGTGCCGTTAATAAAAATTG & BGA66 \\
\hline BGA67s & ATGCGGCCGATCAAGTGCAACGTATTIT & BGA67 \\
\hline BGA67as & GTGGGATCCCATGTGCCGTTAATAAAAATTG & BGA67 \\
\hline BGA68s & ATGCGGCCGACATTATTGTTTTAGTTTGGACTCT & BGA68 \\
\hline BGA68as & GTGGGATCCCATGTGCTGATAAAACC & BGA68 \\
\hline BGA71s & ATGCGGCCCATTGTTGTIITGGTTAAGACTC & BGA71 \\
\hline BGA71as & GTGGGATCCCATGTGTGCTGTTGATAAAATAG & BGA71 \\
\hline qFlaBs & GCTTCTGATGATGCTGCTG & FlaB \\
\hline qFlaBas & TCGTCTGTAAGTTGCTCTATTTC & $\mathrm{FlaB}$ \\
\hline qFlaB Taqmanprobe & GAATTRGCAGTAACGG-FAM & FlaB \\
\hline qBGA66s & AGTTGTGCAGCAGCAATTTT & BGA66 \\
\hline qBGA66as & ATCCAGATCCTTTAAAGAC & BGA66 \\
\hline qBGA71s & TTCATATAGGTTGCTAATGCG & BGA71 \\
\hline qBGA71as & TTGCACACTCAAAACCAAAAA & BGA71 \\
\hline
\end{tabular}


Bioscience, Freiburg, Germany). The ligation mixtures were used to transform Escherichia coli MC1061. Plasmid DNA was prepared from the presumptive clones with the QIAprep kit (QIAGEN, Hilden, Germany), and the Borrelia DNA inserts were sequenced using the BigDye Terminator cycle sequencing kit (Applied Biosystems International, Foster City, CA, USA) in accordance with the manufacturers' recommendations. Plasmids were used to transform E. coli BL21. Expression of the GST fusion proteins was done by induction of the respective BL21 clones induced for 5 hours with $1 \mathrm{mM} \mathrm{IPTG}$, followed by affinity purification with glutathione-Sepharose 4B (GE Healthcare, Netherlands). Expression and purity of generated GST fusion proteins were confirmed by employing SDS-PAGE, and protein concentrations were determined by a Bradford assay (Bio-Rad, Munich, Germany).

\section{Real Time-PCR analysis}

For determining expression in vitro cultures of PBi spirochetes grown to mid log phase were isolated. Nucleic acid was extracted with a QiaAmp Mini Blood DNA kit (Qiagen, Hilden, Germany).

Total nucleic acid was treated with DNAse and $1 \mu \mathrm{g}$ RNA was reverse transcribed using iScript (Bio-Rad) according to the manufacturer's protocol. Primers and probe for the $f l a B$ gene were designed from an interspecies conserved region of $f l a B$ using the Beacondesigner and listed in table 2. Amplification reactions were performed in a $50-\mu \mathrm{l}$ final volume, containing $25 \mu \mathrm{l}$ IQ Supermix (Bio-Rad, Veenendaal, The Netherlands), 15 pmol forward primer, $15 \mathrm{pmol}$ reverse primer, $2.5 \mathrm{mM}$ $\mathrm{MgCl}_{2}, 0.3 \mu \mathrm{M}$ FlaB-probe, or $1 \times$ Sybergreen (Molecular Probes), and $10 \mu \mathrm{l} c D N A$. Following an enzyme activation step for $3 \mathrm{~min}$ at $95^{\circ} \mathrm{C}$, amplification comprised 50 cycles of $30 \mathrm{sec}$ at $95^{\circ} \mathrm{C}, 30 \mathrm{~s}$ at $55^{\circ} \mathrm{C}$ and $30 \mathrm{~s}$ at $72^{\circ}$ $\mathrm{C}$ in an iCycler IQ real-time detection system (Bio-Rad). The FlaB assay was optimized using a TA vector into which the complete $f l a B$ encoding gene from $B$. burgdorferi ss B31 had been cloned and had an analytical sensitivity of 1 copy per PCR in $0.9 \%$ saline.

Quantitative DNA analysis was performed using the Icycler IQ5 PCR system.

The relative starting copy number was determined by cycle threshold detection using Icycler relative quantification software (Roche).

\section{SDS-PAGE, ligand affinity blot analysis, and Western blotting}

Purified recombinant fusion proteins (500 ng) were subjected to $10 \%$ Tris/Tricine-SDS-PAGE under reducing conditions and transferred to nitrocellulose as previously described [16,55]. Briefly, after transfer of proteins onto nitrocellulose, nonspecific binding sides were blocked using $5 \%(\mathrm{w} / \mathrm{v})$ dried milk in TBS $(50$
$\mathrm{mM}$ Tris- $\mathrm{HCl}$ (pH 7.5), $200 \mathrm{mM} \mathrm{NaCl}, 0.1 \%$ Tween 20 for 1 hour at room temperature. Subsequently, membranes were rinsed four times in TBS and incubated for 1 hour at room temperature with TBS containing recombinant FHL-1, pooled non-immune human serum (NHS), or non-immune animal sera. To detect the fusion proteins a goat anti-GST antibody (dilution 1:2,000) (GE Healthcare, Germany) was used. Polyclonal rabbit anti-SCR1-4 antiserum ( $\alpha$ SCR1-4) (dilution 1:1,000) used for the detection of FHL-1 and monoclonal antibody (mAb) VIG8 (undiluted) against the Cterminus of $\mathrm{CFH}$, are described elsewhere $[15,56]$. After four washings with $50 \mathrm{mM}$ Tris- $\mathrm{HCl}$ (pH 7.5)$150 \mathrm{mM} \mathrm{NaCl}-0.2 \%$ Tween 20 (TBST), membranes were incubated for 1 hour with either a polyclonal rabbit antiserum recognizing the $\mathrm{N}$-terminal region of $\mathrm{CFH}(\alpha \mathrm{SCR} 1-4)$ or mAb VIG8, directed against the Cterminus of CFH. Following four washes with TBST, strips were incubated with a peroxidase-conjugated anti-rabbit IgG antibody or with a peroxidase-conjugated anti-mouse IgG antibody (DAKO, Glostrup, Denmark) for 1 hour at room temperature. Detection of bound antibodies was performed by using 3, 3', 5, 5 '-tetramethylbenzidine as substrate.

\section{ELISA}

Recombinant proteins (500 ng/well) were immobilized on wells of a microtiter plate overnight at $4^{\circ} \mathrm{C}$. Unspecific binding sites were blocked with $0.1 \%$ gelatin in PBS for $6 \mathrm{~h}$ at $4^{\circ} \mathrm{C}$. CFH (Calbiochem), or recombinant FHL-1 was added to the wells and left overnight at $4^{\circ} \mathrm{C}$. Polyclonal goat anti-CFH antibody (Calbiochem) was added for $3 \mathrm{~h}$ at room temperature, protein complexes were identified using secondary horseradish peroxidase-coupled antiserum. The reaction was developed with 1,2-phenylenediamine dihydrochloride (Dako-Cytomation), and absorbence was measured at $490 \mathrm{~nm}$.

\section{Binding domains of CFH and FHL-1 to CspA orthologs}

To identify domains of CFH and FHL-1 responsible for binding of BGA66 and BGA71, 500 ng purified recombinant protein was separated by $10 \%$ Tris/Tricine SDSPAGE and transferred to nitrocellulose. Membranes were then incubated with either recombinant FHL-1 (FH1-7), deletion constructs of CFH (FH1-2, FH1-3, FH1-4, FH1-5, FH1-6, FH8-20, FH19-20), or human serum as source for $\mathrm{CFH}$. Bound proteins were visualized using polyclonal goat anti-CFH antibody (Calbiochem), or mAb VIG8.

\section{Statistical analysis}

All statistical analyses were done using SPSS 16.0 and Microsoft Excel software. The two-tailed Student t-test 
was used to analyze ELISA results. Values of $\mathrm{p}<0.05$ were considered to be significant.

\section{Abbreviations}

BSK-H: modified Barbour-Stoenner-Kelly medium; $\mathrm{CFH}$ : factor $\mathrm{H}$; FHL-1: Factor $\mathrm{H}$ like; CRASP: Complement Regulator Acquiring Surface Protein; HI: heat inactivated; IF: Immunofluorescence; mAB: monoclonal antibody; NHS; nonimmune human serum; SCR: short consensus repeats; SDS-PAGE; sodium dodecyl sulfate - polyacrylamide gel electrophoresis; ST4: OspA serotype 4; PBS: phosphate-buffered saline

\section{Acknowledgements}

We thank Bettina Wilske for providing B. garinii ST4 strain PBi, and Christa Hanssen-Hübner and Angela van Weert for expert technical assistance. We also thank Pulak Goswami for reviewing the English version of this manuscript. This work was funded by the Deutsche Forschungsgemeinschaft grant Kr3383/1-2 to P. Kraiczy.

\section{Author details}

'Department of Medical Microbiology, Centre of Infectious Diseases, Leiden University Medical Centre, PO Box 9600, 2300 RC, Leiden, the Netherlands. ${ }^{2}$ Institute of Medical Microbiology and Infection Control, University Hospital of Frankfurt, Paul-Ehrlich-Str. 40, D-60596 Frankfurt, Germany. ${ }^{3}$ Department of Infection Biology, Leibniz-Institute for Natural Products Research, Beutenbergstr.11a, 07745 Jena, Germany.

\section{Authors' contributions}

NDvB and APvD conceived of the study. NDvB performed serum killing assays, PCR cloning and performed ligand affinity blots and ELISA and drafted the manuscript. PK supervised protein assays and performed cell binding assays and protease assay and edited the manuscript. TJS performed IF experiments. PFZ was responsible for all recombinant CFH and FHL-1 protein assays. APvD supervised the work and edited the manuscript. All authors read and approved the final manuscript.

Received: 22 September 2009

Accepted: 10 February 2010 Published: 10 February 2010

\section{References}

1. van Dam AP, Kuiper H, Vos K, Widjojokusumo A, de Jongh BM, Spanjaard L, et al: Different genospecies of Borrelia burgdorferi are associated with distinct clinical manifestations of Lyme borreliosis. Clin Infect Dis 1993, 17:708-717.

2. Saint GI, Gern L, Gray JS, Guy EC, Korenberg E, Nuttall PA, et al: Identification of Borrelia burgdorferi sensu lato species in Europe. Zentralbl Bakteriol 1998, 287:190-195.

3. Wilske B, Busch U, Eiffert H, Fingerle V, Pfister HW, Rossler D, et al: Diversity of OspA and OspC among cerebrospinal fluid isolates of Borrelia burgdorferi sensu lato from patients with neuroborreliosis in Germany. Med Microbiol Immunol 1996, 184:195-201.

4. Marconi RT, Hohenberger S, Jauris-Heipke S, Schulte-Spechtel U, Lavoie CP, Rossler D, et al: Genetic analysis of Borrelia garinii OspA serotype 4 strains associated with neuroborreliosis: evidence for extensive genetic homogeneity. J Clin Microbiol 1999, 37:3965-3970.

5. Wilske B, Busch U, Fingerle V, Jauris-Heipke S, Preac MV, Rossler D, et al: Immunological and molecular variability of OspA and OspC. Implications for Borrelia vaccine development. Infection 1996, 24:208-212

6. Wilske B, Preac-Mursic V, Gobel UB, Graf B, Jauris S, Soutschek E, et al: An OspA serotyping system for Borrelia burgdorferi based on reactivity with monoclonal antibodies and OspA sequence analysis. $J$ Clin Microbiol 1993, 31:340-350.

7. Margos G, Vollmer SA, Cornet M, Garnier M, Fingerle V, Wilske B, et al: MLSA on housekeeping genes defines a new Borrelia species. Appl Environ Microbiol 2009, 75:5410-5416.

8. Breitner-Ruddock S, Wurzner $\mathrm{R}$, Schulze J, Brade V: Heterogeneity in the complement-dependent bacteriolysis within the species of Borrelia burgdorferi. Med Microbiol Immunol (Berl) 1997, 185:253-260.
9. Kurtenbach K, Sewell HS, Ogden NH, Randolph SE, Nuttall PA: Serum complement sensitivity as a key factor in Lyme disease ecology. Infect Immun 1998, 66:1248-1251.

10. van Dam AP, Oei A, Jaspars R, Fijen C, Wilske B, Spanjaard L, et al: Complement-mediated serum sensitivity among spirochetes that cause Lyme disease. Infect Immun 1997, 65:1228-1236.

11. Zipfel PF, Skerka C: Complement regulators and inhibitory proteins. Nat Rev Immunol 2009, 9:729-740

12. Zipfel PF, Skerka C, Hellwage J, Jokiranta ST, Meri S, Brade V, et al: Factor H family proteins: on complement, microbes and human diseases. Biochem Soc Trans 2002, 30:971-978.

13. Pangburn MK, Schreiber RD, Muller-Eberhard HJ: Human complement C3b inactivator: isolation, characterization, and demonstration of an absolute requirement for the serum protein beta1H for cleavage of $\mathrm{C} 3 \mathrm{~b}$ and $\mathrm{C} 4 \mathrm{~b}$ in solution. J Exp Med 1977, 146:257-270.

14. Kuhn S, Zipfel PF: Mapping of the domains required for decay acceleration activity of the human factor $\mathrm{H}$-like protein 1 and factor $\mathrm{H}$. Eur J Immunol 1996, 26:2383-2387.

15. Kuhn S, Skerka C, Zipfel PF: Mapping of the complement regulatory domains in the human factor $\mathrm{H}$-like protein 1 and in factor $\mathrm{H} 1 . J$ Immunol 1995, 155:5663-5670.

16. Kraiczy P, Skerka C, Brade V, Zipfel PF: Further characterization of complement regulator-acquiring surface proteins of Borrelia burgdorferi. Infect Immun 2001, 69:7800-7809.

17. Kraiczy P, Rossmann E, Brade V, Simon MM, Skerka C, Zipfel PF, et al: Binding of human complement regulators FHL-1 and factor $\mathrm{H}$ to CRASP1 orthologs of Borrelia burgdorferi. Wiener Klinische Wochenschrift 2006 118:669-676

18. Bykowski T, Woodman ME, Cooley AE, Brissette CA, Wallich R, Brade V, et al: Borrelia burgdorferi complement regulator-acquiring surface proteins (BbCRASPs): Expression patterns during the mammal-tick infection cycle. Int J Med Microbiol 2008, 298(Suppl 1):249-256.

19. Bykowski T, Woodman ME, Cooley AE, Brissette CA, Brade V, Wallich R, et al: Coordinated expression of Borrelia burgdorferi complement regulatoracquiring surface proteins during the Lyme disease spirochete's mammal-tick infection cycle. Infect Immun 2007, 75:4227-4236.

20. Rogers EA, Abdunnur SV, McDowell JV, Marconi RT: Comparative analysis of the properties and ligand binding characteristics of CspZ, a factor $\mathrm{H}$ binding protein, derived from Borrelia burgdorferi isolates of human origin. Infect Immun 2009, 77:4396-4405.

21. Hartmann K, Corvey C, Skerka C, Kirschfink M, Karas M, Brade V, et al: Functional characterization of BbCRASP-2, a distinct outer membrane protein of Borrelia burgdorferi that binds host complement regulators factor $\mathrm{H}$ and FHL-1. Mol Microbiol 2006, 61:1220-1236.

22. Rogers EA, Marconi RT: Delineation of species-specific binding properties of the CspZ protein (BBH06) of Lyme disease spirochetes: evidence for new contributions to the pathogenesis of Borrelia spp. Infect Immun 2007, 75:5272-5281.

23. Zhang H, Marconi RT: Demonstration of cotranscription and 1-methyl-3nitroso-nitroguanidine induction of a 30-gene operon of Borrelia burgdorferi: evidence that the 32-kilobase circular plasmids are prophages. J Bacteriol 2005, 187:7985-7995.

24. Brissette CA, Verma A, Bowman A, Cooley AE, Stevenson B: The Borrelia burgdorferi outer-surface protein ErpX binds mammalian laminin. Microbiology 2009, 155:863-872.

25. Miller JC, Stevenson B: Borrelia burgdorferi erp genes are expressed at different levels within tissues of chronically infected mammalian hosts. Int J Med Microbiol 2006, 296:185-194.

26. Miller JC, Narayan K, Stevenson B, Pachner AR: Expression of Borrelia burgdorferi erp genes during infection of non-human primates. Microb Pathog 2005, 39:27-33.

27. Miller JC, Stevenson B: Increased expression of Borrelia burgdorferi factor $\mathrm{H}$-binding surface proteins during transmission from ticks to mice. Int $\mathrm{J}$ Med Microbiol 2004, 293(Suppl 37):120-125.

28. Miller JC, von Lackum K, Babb K, McAlister JD, Stevenson B: Temporal analysis of Borrelia burgdorferi Erp protein expression throughout the mammal-tick infectious cycle. Infect Immun 2003, 71:6943-6952.

29. Metts MS, McDowell JV, Theisen M, Hansen PR, Marconi RT: Analysis of the OspE determinants involved in binding of factor $\mathrm{H}$ and OspE-targeting antibodies elicited during Borrelia burgdorferi infection in mice. Infect Immun 2003, 71:3587-3596. 
30. Kraiczy P, Skerka C, Kirschfink M, Brade V, Zipfel PF: Immune evasion of Borrelia burgdorferi by acquisition of human complement regulators FHL-1/reconectin and Factor H. Eur J Immunol 2001, 31:1674-1684.

31. Wallich R, Pattathu J, Kitiratschky V, Brenner C, Zipfel PF, Brade V, et al: Identification and functional characterization of complement regulatoracquiring surface protein 1 of the Lyme disease spirochetes Borrelia afzelii and Borrelia garinii. Infect Immun 2005, 73:2351-2359.

32. McDowell JV, Harlin ME, Rogers EA, Marconi RT: Putative coiled-coil structural elements of the BBA68 protein of Lyme disease spirochetes are required for formation of its factor $\mathrm{H}$ binding site. J Bacteriol 2005, 187:1317-1323.

33. McDowell JV, Wolfgang J, Tran E, Metts MS, Hamilton D, Marconi RT: Comprehensive analysis of the factor $\mathrm{h}$ binding capabilities of borrelia species associated with lyme disease: delineation of two distinct classes of factor $\mathrm{h}$ binding proteins. Infect Immun 2003, 71:3597-3602.

34. Kraiczy P, Hellwage J, Skerka C, Becker H, Kirschfink M, Simon MM, et al: Complement resistance of Borrelia burgdorferi correlates with the expression of BbCRASP-1, a novel linear plasmid-encoded surface protein that interacts with human factor $\mathrm{H}$ and $\mathrm{FHL}-1$ and is unrelated to Erp proteins. J Biol Chem 2004, 279:2421-2429.

35. Kraiczy P, Hanssen-Hubner C, Kitiratschky V, Brenner C, Besier S, Brade V, et al: Mutational analyses of the BbCRASP-1 protein of Borrelia burgdorferi identify residues relevant for the architecture and binding of host complement regulators FHL-1 and factor H. Int J Med Microbiol 2009, 299:255-268.

36. Cordes FS, Kraiczy P, Roversi P, Simon MM, Brade V, Jahraus O, et al: Structure-function mapping of BbCRASP-1, the key complement factor $\mathrm{H}$ and FHL-1 binding protein of Borrelia burgdorferi. Int J Med Microbiol 2006, 296(Suppl 40):177-184.

37. Cordes FS, Roversi $P$, Kraiczy $P$, Simon MM, Brade $V$, Jahraus $O$, et al: A novel fold for the factor $\mathrm{H}$-binding protein BbCRASP-1 of Borrelia burgdorferi. Nat Struct Mol Biol 2005, 12:276-277.

38. Kraiczy P, Hunfeld KP, Breitner-Ruddock S, Wurzner R, Acker G, Brade V: Comparison of two laboratory methods for the determination of serum resistance in Borrelia burgdorferi isolates. Immunobiology 2000, 201:406-419.

39. Herzberger $P$, Siegel C, Skerka C, Fingerle V, Schulte-Spechtel U, van DA, et al: Human pathogenic Borrelia spielmanii sp. nov. resists complementmediated killing by direct binding of immune regulators factor $\mathrm{H}$ and factor H-like protein 1. Infect Immun 2007, 75:4817-4825.

40. Wang G, van Dam AP, Spanjaard L, Dankert J: Molecular typing of Borrelia burgdorferi sensu lato by randomly amplified polymorphic DNA fingerprinting analysis. J Clin Microbiol 1998, 36:768-776.

41. Busch U, Hizo-Teufel C, Boehmer R, Fingerle V, Nitschko H, Wilske B, et al: Three species of Borrelia burgdorferi sensu lato (B. burgdorferi sensu stricto, B afzelii, and B. garinii) identified from cerebrospinal fluid isolates by pulsed-field gel electrophoresis and PCR. J Clin Microbiol 1996, 34:1072-1078.

42. Brooks CS, Vuppala SR, Jett AM, Alitalo A, Meri S, Akins DR: Complement regulator-acquiring surface protein 1 imparts resistance to human serum in Borrelia burgdorferi. J Immunol 2005, 175:3299-3308.

43. Kenedy MR, Vuppala SR, Siegel C, Kraiczy P, Akins DR: CspA-mediated binding of human factor $\mathrm{H}$ inhibits complement deposition and confers serum resistance in Borrelia burgdorferi. Infect Immun 2009, 77:2773-2782.

44. Oliver MA, Rojo JM, Rodriguez de CS, Alberti S: Binding of complement regulatory proteins to group A Streptococcus. Vaccine 2008, 26(Suppl 8): 175-178.

45. Ngampasutadol J, Ram S, Gulati S, Agarwal S, Li C, Visintin A, et al: Human factor $\mathrm{H}$ interacts selectively with Neisseria gonorrhoeae and results in species-specific complement evasion. J Immunol 2008, 180:3426-3435.

46. Beernink PT, Caugant DA, Welsch JA, Koeberling O, Granoff DM: Meningococcal factor $\mathrm{H}$-binding protein variants expressed by epidemic capsular group A, W-135, and X strains from Africa. J Infect Dis 2009, 199:1360-1368

47. Oppermann M, Manuelian T, Jozsi M, Brandt E, Jokiranta TS, Heinen S, et al: The $\mathrm{C}$-terminus of complement regulator Factor $\mathrm{H}$ mediates target recognition: evidence for a compact conformation of the native protein. Clin Exp Immunol 2006, 144:342-352.

48. Hellwage J, Meri T, Heikkila T, Alitalo A, Panelius J, Lahdenne P, et al: The complement regulator factor $\mathrm{H}$ binds to the surface protein OspE of Borrelia burgdorferi. J Biol Chem 2001, 276:8427-8435.
49. Stevenson B, von Lackum K, Riley SP, Cooley AE, Woodman ME, Bykowski T: Evolving models of Lyme disease spirochete gene regulation. Wien Klin Wochenschr 2006, 118:643-652.

50. Rossmann E, Kitiratschky V, Hofmann H, Kraiczy P, Simon MM, Wallich R: Borrelia burgdorferi complement regulator-acquiring surface protein 1 of the Lyme disease spirochetes is expressed in humans and induces antibody responses restricted to nondenatured structural determinants. Infect Immun 2006, 74:7024-7028.

51. Lederer S, Brenner C, Stehle T, Gern L, Wallich R, Simon MM: Quantitative analysis of Borrelia burgdorferi gene expression in naturally (tick) infected mouse strains. Med Microbiol Immunol 2005, 194:81-90.

52. Wallich R, Jahraus O, Stehle T, Tran T, Brenner C, Hofmann $H$, et al: Artificial-infection protocols allow immunodetection of novel Borrelia burgdorferi antigens suitable as vaccine candidates against Lyme disease. Eur J Immunol 2003, 33:708-719.

53. Bhide MR, Escudero R, Camafeita E, Gil H, Jado I, Anda P: Complement factor $\mathrm{H}$ binding by different Lyme disease and relapsing fever Borrelia in animals and human. BMC Res Notes 2009, 2:134.

54. Schuijt TJ, Hovius JW, van Burgel ND, Ramamoorthi N, Fikrig E, van Dam AP. The tick salivary protein Salp15 inhibits the killing of serum-sensitive Borrelia burgdorferi sensu lato isolates. Infect Immun 2008, 76:2888-2894.

55. Kraiczy P, Hellwage J, Skerka C, Kirschfink M, Brade V, Zipfel PF, et al: Immune evasion of Borrelia burgdorferi: mapping of a complementinhibitor factor H-binding site of BbCRASP-3, a novel member of the Erp protein family. Eur J Immunol 2003, 33:697-707.

56. Prodinger WM, Hellwage J, Spruth M, Dierich MP, Zipfel PF: The C-terminus of factor $\mathrm{H}$ : monoclonal antibodies inhibit heparin binding and identify epitopes common to factor $\mathrm{H}$ and factor $\mathrm{H}$-related proteins. Biochem $\mathrm{J}$ 1998, 331(Pt 1):41-47.

doi:10.1186/1471-2180-10-43

Cite this article as: van Burgel et al:: Identification and functional characterisation of Complement Regulator Acquiring Surface Protein-1 of serum resistant Borrelia garinii OspA serotype 4. BMC Microbiology 2010 10:43.

\section{Submit your next manuscript to BioMed Central and take full advantage of:}

- Convenient online submission

- Thorough peer review

- No space constraints or color figure charges

- Immediate publication on acceptance

- Inclusion in PubMed, CAS, Scopus and Google Scholar

- Research which is freely available for redistribution 